\title{
Tuning Your Fuel-Gas Delivery System
}

\author{
T.D. Newbound and K.S. Al-Showiman \\ Saudi Arabian Oil Company (Saudi Aramco) \\ Dhahran, Saudi Arabia
}

\begin{abstract}
Saudi Aramco has focused more attention in recent years on fuel gas conditioning for land-based industrial and aeroderivative combustion gas turbines CGTs. Hydrocarbon dew points and entrained solids are two important fuel quality issues that frequently trouble CGT operators, partly because they cannot be guaranteed by the fuel suppliers and they are rarely monitored by the operators. This paper addresses these issues and offers some practical advice to optimize the design and operation of fuel gas delivery systems.
\end{abstract}

Saudi Aramco has been testing an automated on-line dew point monitor capable of detecting both hydrocarbon and aqueous dew points in natural gas. Dew point monitoring conducted at three locations on the fuel gas grid revealed wide variations in the hydrocarbon and aqueous dew points due to a variety of conditions. Gas production and pipeline operations were responsible for the most dramatic variations in dew points, but exposure of pipelines to the weather can also be important.

Measurement of pipeline solids for the purpose of sizing and placement of particle filters have also been explored. Pipeline scraping, gas velocities, length of pipeline span, pipeline junctions and control valves are all considerations for solid control strategies.

The optimized design and operation of a CGT fuel system is highly dependent on dew point control and efficient removal of entrained pipeline solids. Practical experience in monitoring hydrocarbon and aqueous dew points, pipeline solids control, and optimizing fuel conditioning equipment will be presented.

\section{INTRODUCTION}

Saudi Arabia's main source of electrical power is provided by CGT generators (CGTGs). Most of the CGTGs operating in the Eastern and Central Regions of Saudi Arabia are currently fueled by natural gas. This has been made possible by a rapidly growing sweet gas industry comprised of five major gas processing plants and thousands of kilometers of gas pipelines. As new gas sources, processing facilities and pipelines have been added to the gas grid, the system as a whole has become increasingly more complex and diagnosis of irregularities in gas composition more challenging. While Saudi Aramco's sales gas specifications mirror sales gas standards worldwide, these standards do not guarantee adequate fuel condition for operating CGTs.

One gas fuel specification generally required by CGT manufacturers, but not part of sales gas specifications, is the 50 ${ }^{\circ} \mathrm{F}$ superheat requirement. That is, inlet fuel gas temperatures must be at least $50{ }^{\circ} \mathrm{F}\left(28{ }^{\circ} \mathrm{C}\right)$ or above the dew point calculated from the fuel gas composition. The safety margin imposed by the superheat margin mainly allows for Joules Thomson cooling as fuel expands through its path to the combustion chamber. There is some room for error in the measurement of fuel gas compositions, but accuracy is important, especially in the C6+ range where small errors in the concentrations of heavy hydrocarbons can translate to large dew point shifts. Perhaps more important is the potential for gas compositions to vary within any given 24 hour period due to gas process changes, pipeline operations and even changes in the weather. Of course, the potential for these changes will depend on the sources of the fuel gas, complexity of the fuel gas system and the environment.

Another requirement for CGT gas fuel is that it must be delivered free of solids. Some sales gas contracts have general statements addressing solids, but none to our knowledge have defined a quantitative limit for solids. Perhaps this is because there is no recognized standard for measuring solids entrained in natural gas pipelines.

Previous publications have addressed methods of measuring fuel gas dew points and fuel treatment to eliminate liquids [1]. 
We have recently published findings from the first two phases of our dew point monitoring campaign [2]. These and other publications describe the distress to CGT hot gas path parts that can result from liquid carry-over [3]. There are plenty of products on the market to treat most any fuel gas condition, but careful diagnosis of fuel gas condition over an adequate time period is where many operators fail to zero in on their fuel treatment needs. Realization of this gap led Saudi Aramco to begin a dew point monitoring campaign on its fuel gas grid.

\section{DISCUSSION}

Dew Point Determinations. Detection of entrained liquids in natural gas fuel supplies is difficult and not practical for continuous on-line fuel gas analysis. However, determination of aqueous and hydrocarbon dew points can predict conditions that are favorable for liquid formation. Although it has been common practice for the design basis of CGT fuel systems to be based on single (spot) sample analyses, on-line monitoring has become much more practical, especially where multiple CGTs are operated on the same fuel source. Improvements and cost reductions in microprocessors over the past 10 years have made automated fuel monitoring more reliable and affordable.

The gas chromatograph (GC) is the most widely used on-line analytical tool for fuel gas analysis, although it is usually used for heating value determinations (determines hydrocarbons groups up to $\mathrm{C}^{+}+$). There are commercial GCs equipped for extended gas analysis that are capable of resolving individual hydrocarbon groups out to $\mathrm{C} 8$ and $\mathrm{C} 9+$. These instruments now have a relatively short analytical cycle (5-10 minutes) and are capable of high reproducibility within $5^{\circ} \mathrm{C}$ of the actual hydrocarbon dew point. Furthermore, they tolerate corrosive gases such as $\mathrm{H}_{2} \mathrm{~S}$ and $\mathrm{CO}_{2}$. However, without the extended capability to analyze $\mathrm{C} 9+$, they are of little value for dew point monitoring. GCs configured to monitor hydrocarbons cannot also measure moisture in gas.

Direct dew point measurements using an automated Bureau-ofMines dew point monitor can afford highly accurate dew point measurements for hydrocarbon dew points between $-40{ }^{\circ} \mathrm{C}$ to $+35^{\circ} \mathrm{C}$. Saudi Aramco has been operating an Ametek Model 241 dew point analyzer for four consecutive years at three sites on the fuel gas grid in Eastern and Central Provinces of Saudi Arabia. During the first two phases of monitoring activity, hydrocarbon dew points in sales gas were observed to vary as much as $40^{\circ} \mathrm{F}$ in one 24 hour period primarily due to gas plant operations (Figure 1). It was later shown that hydrocarbon dew points combined with CGTG control data provided direct indications of liquid hydrocarbon carry-over past the CGT fuel control valve (Figure 2).

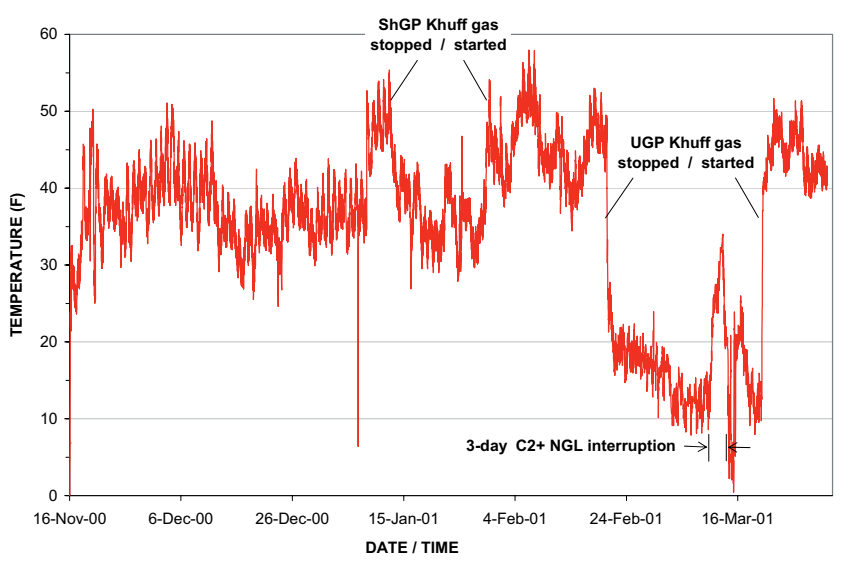

Figure 1 Hydrocarbon dew points recorded over a three month period reveal dramatic changes that coincide with major operational events in the gas plants.

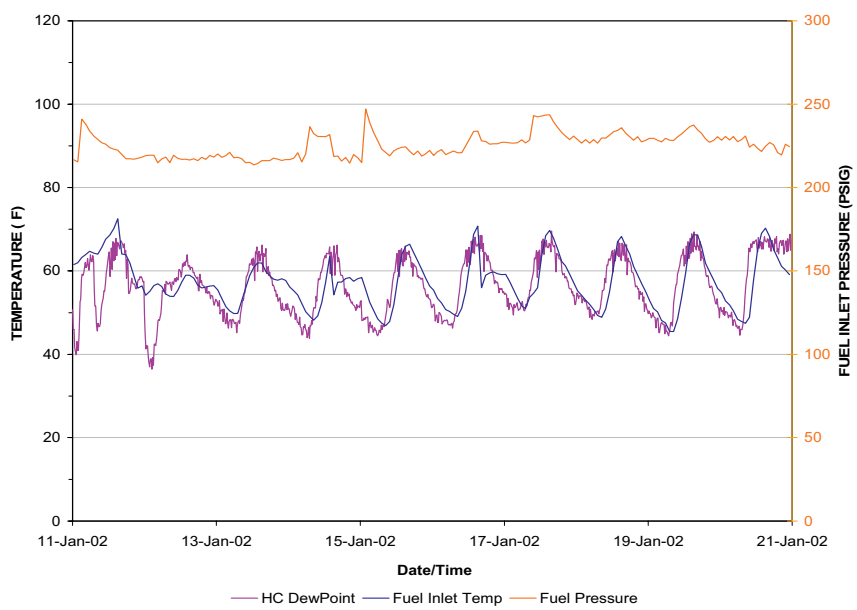

Figure 2 Hydrocarbon dew points plotted with archived fuel inlet temperature and pressure for one CGTG unit at a power plant feed by the local fuel gas system near the central Ghawar region gas plant UGP. Note that saturated fuel gas conditions coincide with elevated fuel pressure.

In the current phase of monitoring on Saudi Arabia's East/West Pipeline, water dew points were observed for the first time above the hydrocarbon dew points. Previously, water dew points were not observed because they were always below the hydrocarbon dew points, and the monitor is programmed to terminate the cooling cycle when it finds the hydrocarbon dew point. Otherwise, the monitor would not readily recognize the water condensation point on surfaces that are already coated with liquid hydrocarbon.

Gas transported though the East / West Pipeline is primarily derived from three gas processing plants: UGP, HGP, and HDGP. Average daily production rates are compared in Figure 3. Gas from these sources is combined in stages, eventually joining the pipeline that feeds the dew point monitoring site. Thus, tracing the source of moisture was not straight forward. 


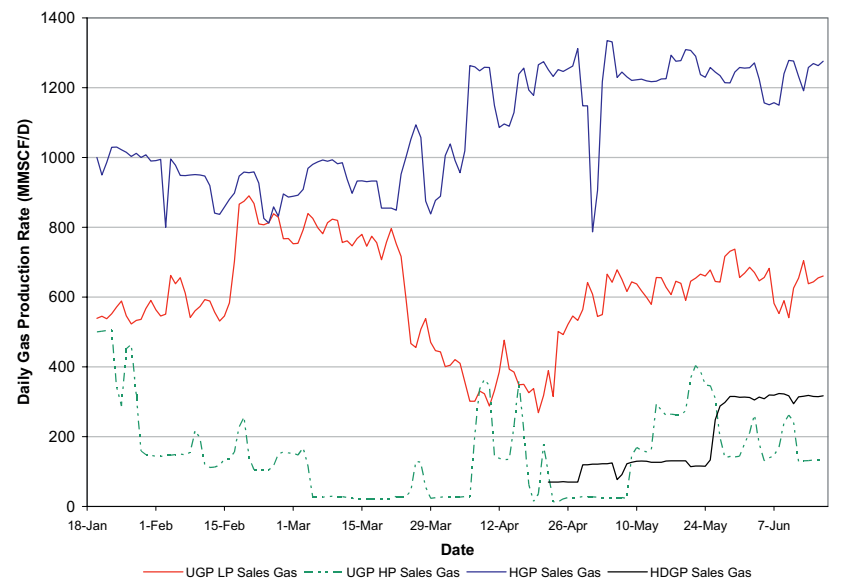

Figure 3 Average daily production rates from South Ghawar Gas Plants.

The first appearance of moisture (January 20, 2003, Figure 4) coincides with a significant drop in the production rate of a gas processing module from UGP. This module processes gas derived from gas-only wells ("Khuff reservoir"). The Khuff gas is processed at higher pressure with higher temperature liquid recovery and less stringent dehydration. Consequently, the Khuff gas has more $\mathrm{C} 6+$ and has more moisture relative to gas processed from the low pressure associated gas processing modules. The reduction of Khuff gas produced from the UGP high pressure module appears to coincide with a drop in the hydrocarbon dew point, although less dramatic than its effect in 2001 when HGP was not producing gas (cf. Figure 1). In this case HGP gas becomes a larger fraction of the overall sales gas, but this does not explain the high level of moisture.

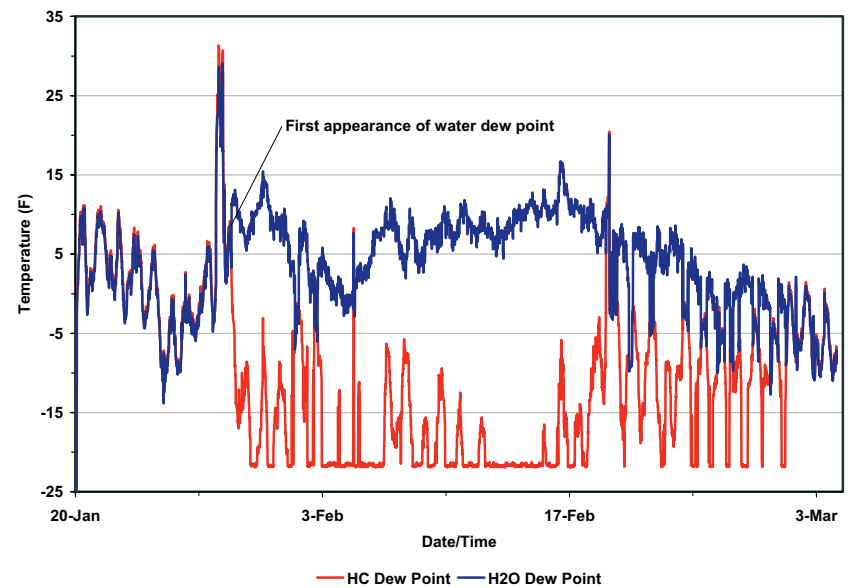

Figure 4 On-Line hydrocarbon and water dew points recorded with the Ametek 241 CE dew point monitor at Pump Station-3 (SRG-1 sales gas).

Further inquiries led to information about a new pipeline installation from HDGP to UGP, which had just recently undergone a hydrotest. The hydrotest drying protocol were conducted during February and March before the pipeline was finally commissioned on April 28. The commissioning of the new pipeline coincided with the first production from the new gas plant "HDGP". Following the opening of the new gas plant and pipeline to the sales gas system, the water dew points were recorded in a regular pattern exceeding the $7 \mathrm{lbs} / \mathrm{MMSCF}(20$ ${ }^{\circ} \mathrm{F}$ for $550 \mathrm{psig}$ ) sales gas specification for moisture (Figure 7). Peak water dew points were recorded at $32{ }^{\circ} \mathrm{F}$, which at 550 psig equates to $11 \mathrm{lbs} / \mathrm{MMSCF}$. The high moisture contents persisted for about two months. Fortunately, this event occurred during a relatively warm season when gas temperatures were above $85^{\circ} \mathrm{F}$. Thus, no incidents from use of sales gas were reported as a consequence of high dew points.

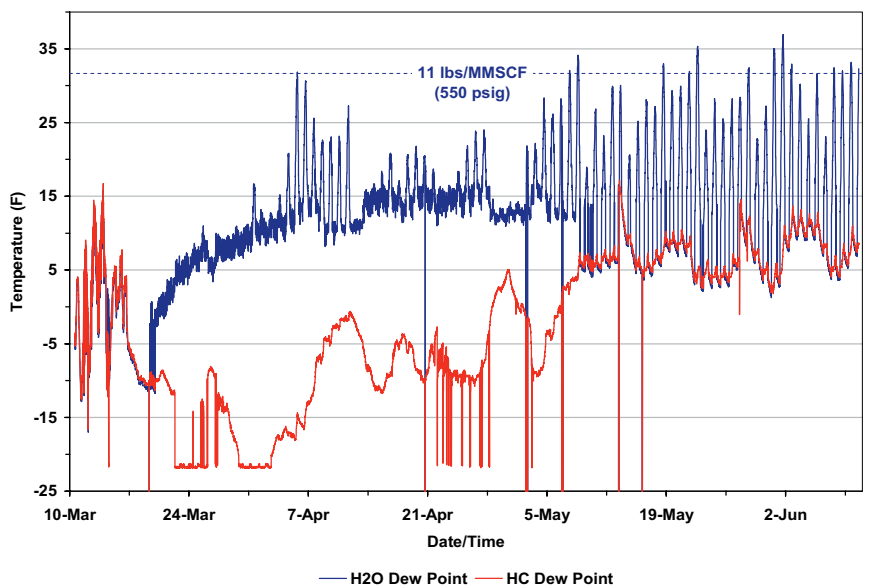

Figure 5 On-Line hydrocarbon and water dew points recorded with the Ametek $241 \mathrm{CE}$ dew point monitor at E/W Pipeline Pump Station-3 from March 10June 10, 2003.

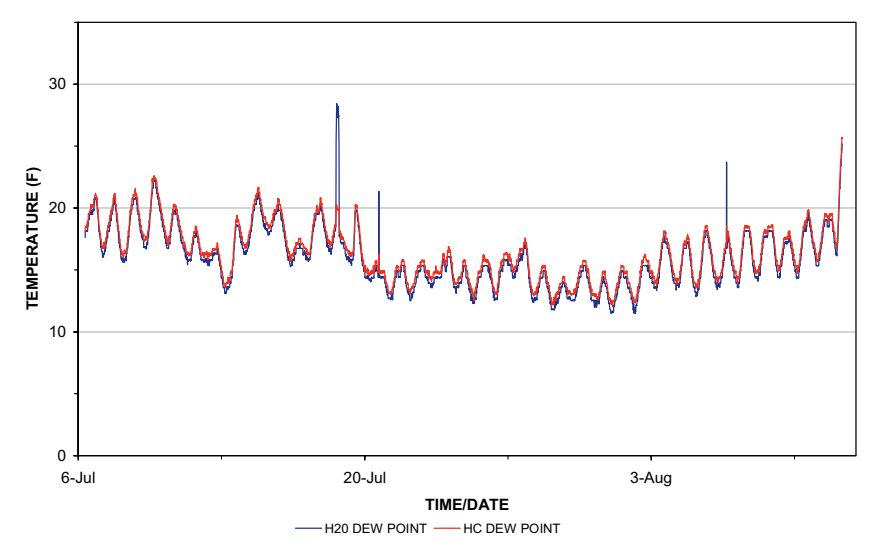

Figure 6 On-Line Hydrocarbon and water dew points recorded with the Ametek $241 \mathrm{CE}$ dew point monitor at E/W Pipeline Pump Station-3 from July 7 August 12, 2003.

By August, indications of high moisture had all but completely disappeared. Water dew points dropped below the hydrocarbon dew points and hydrocarbon dew points appeared to stabilize in a familiar pattern, although the average dew points were significantly higher that those observed earlier that year. This is expected as more Khuff gas is produced during the summer to meet the higher demand for energy. 
Pipeline Solids. The Saudi Sales gas grid customers have experienced intermittent filter skid plugging, control valve erosion and plant upsets due to entrained solids. Indeed, worldwide, corrosion solids appear to be the most prominent contamination problem for natural pipelines and compression equipment [4].

Entrainment of solids in natural gas streams involves a complex array of chemical and physical conditions. The composition of pipeline solids, aptly described as "black powder" is generally a blend of iron oxides and iron sulfides derived from pipeline mill scale and chemical sulfidation (reaction of hydrogen sulfide with iron). Moisture can create even more serious problems by activating otherwise dormant microbial corrosion from sulfate reducing bacteria (SRB) and acid producing bacteria (APB). Solids from pipeline hydrotests have also contributed to the solids problem with a variety of iron hydroxides.

Since most CGT operators usually have little if any control over the pipeline operations upstream from their own fuel delivery piping, their only option may be to remove solids at the entrance of their fuel system by some form of filtration or centrifugal separation. Determining which filtration options will be most effective for a particular fuel gas system is often not a trivial task. Where there are existing filters in equivalent locations, or for filter upgrades, it is often possible to collect representative samples of the solids from spent filter cartridges out of existing filters. From these solids it is possible to determine composition particle size distribution, grain density and bulk density. Perhaps it would also be possible to estimate of the quantity of solids over a period of time. The difficulty in measuring quantities of solids at a particular location is that, like dew points, solids entrainment in gas streams may vary from one moment to the next. It can also vary widely from location to location.

One campaign to measure solids entrained at various points in the northern end of Saudi Aramco's Sales gas system was undertaken during summer of 1991. Samples were acquired from six different locations over a nine hour period by flowing a steady state stream of the gas through a solids trap at equivalent flow rates ( $c a .2 \mathrm{SCF} / \mathrm{min}$ ), then measuring the mass of solids collected in the trap. The amounts varied from 0.006 to $94 \mathrm{~g} / \mathrm{MMSCF}$, or more than four orders of magnitude. Although the sampling method used in this study is not a recognized standard method, it illustrates the potential for large variations in the amount of entrained solids from one position to another on a fuel gas grid.

Ostensibly, the entrainment of solids in a pipeline will be dependent on such conditions as flow velocity of gas, geometry of the piping upstream of the sampling point, and the size distribution and particle density of the solids. However, other conditions, such as the presence or absence of residual compressor oils or glycols, high hydrocarbon or water dew points can have significant effects on solids entrainment. Furthermore, pipeline operations, such as opening and closing pipeline bypasses and pipeline scraping can release and entrain solids in sudden and severe slugs.

Filtering. The uncertainty that remains after a careful analysis of pipeline solids generally relates to sizing of filtration apparatus. For example, if large volumes of pipeline solids are expected, it may be necessary to include a cyclone or magnetic trap upstream of the particle filter to remove large volumes of material and avoid having to change filter cartridges on a frequent basis. After particle filters have been put into service, it is important to closely monitor changes in pressure differential across the filter. Filter cartridges should be changed on a regular schedule or sooner if high pressure differential indicates that the filter loading is high. A sudden drop in pressure differential to zero indicates that the filter has been breached and the element should be changed immediately.

Coalescing filters should be located between the particulate filters (upstream) and the gas superheater (downstream). Coalescing filters designed for natural gas fuel systems are generally not designed for and should not be used as solid particulates filters. Coalescing filters with absolute ratings to 0.3 microns are common and available from several manufacturers. With adequate protection from solid particulates, more expensive coalescing filter elements should not require frequent replacement.

Superheating. The final stage of fuel conditioning should be the fuel superheater. To assure that the superheater is truly delivering superheated fuel, the feed to the superheater should be practically free of liquid and solid particulates above 0.3 microns. Regardless of what type of fuel superheater is being used, good pre-filtration is important. This assures that heating actually provides superheat, and not just partial fuel vaporization.

Overheating fuel beyond the minimum superheat will have little effect on the health of the turbine, but is wasteful of energy. It can also decrease the overall power output of the turbine when the fuel supply pressure is limited. Depending upon the circumstances at a particular site, different strategies for applying superheat may be used.

In Phase 1 of our dew point monitoring program, fuel preheating was provided by refinery steam. Energy loss from the use of refinery steam was not as much of a concern as the health and reliability of the refinery's two utility CGTGs. Thus, the refinery Utilities chose to operate their fuel superheaters at $135^{\circ} \mathrm{F}$ year-round.

Dew point monitoring during Phase- 2 revealed that the fuel gas supply for a major power plant in the South Ghawar area was 
saturated in heavy hydrocarbons during cool weather (about 5 out of 12 months/year). Without fuel preheating, liquid hydrocarbons were reaching the CGT hot gas path. Gas fired fuel preheaters that previously had been out of service because they were troublesome to operate, were put back into service, but only during the cool season. Power plant operators were able to set the superheater outlet temperature to approximate minimum superheat conditions and establish the time period that fuel superheating would be necessary.

In Phase-3, the dew points of Sales gas that feeds the entire central region of Saudi Arabia was monitored at a single site. The fuel systems in this region are new and most are equipped with electrical fuel superheaters. By continuing to monitor dew points at this single site, it will be possible to synchronize the entire fleet of operating CGT fuel superheaters in order to provide the minimum energy input to achieve minimum superheat. Although the power required for operating one superheater a few degrees higher than necessary may not amount to much, the savings in energy could be substantial with tight fuel temperature control of an entire fleet of a dozen or more large CGTs.

\section{CONCLUSIONS}

This work emphasizes the benefits of on-line monitoring in gas fuel systems as a means of preventing damage to CGT hot section components, while also saving energy and maximizing the power output potential of the CGT. In cases where it is suspected that damage has occurred to CGTs as a result of liquid carryover, it is often difficult to prove without recorded fuel monitoring.

Sales gas contracts do not provide adequate assurance that fuel properties will meet manufacturer's specifications for CGTs. Although specific limits for moisture, $\mathrm{H}_{2} \mathrm{~S}$ and total sulfur are typically included in sales gas specifications, quantitative limits for entrained solids and hydrocarbon liquids cannot be guaranteed. Documented upset conditions have shown that even moisture cannot be controlled at times.

CGT operators are responsible for providing fuel to their CGTs that meets the OEM specifications. Especially on complex fuel gas grids, only continuous monitoring, not single sample analysis, provides an accurate representation of the range of fuel conditions. The savings from the reduction in CGT repair costs and energy savings in Saudi Arabia as a result of dew point monitoring has been estimated at over $\$ 3$ million per year. The cost of dew point monitoring has been less that $\$ 100$ thousand over the four-year study including the capital cost of the dew point monitor.

Entrained solids have been a growing problem as the Saudi sales gas grid has been expanding. Saudi Aramco has been actively pursuing remedies designed to improve the cleanliness of the sales gas system. Advanced designed pipeline scraping and chemical cleaning methods have been used in an ongoing effort to reduce pipeline solids. Consideration has been given to installing particle separators at strategic pipeline junctions. But ultimately the customers will be required to provide fuel system filters to meet their specific fuel quality specifications.

\section{ACKNOWLEDGMENTS}

The authors wish to express appreciation to Saudi Aramco, and the Saudi Arabian Ministry of Petroleum and Mineral Resources for granting permission to publish this material. Credit is due to many individuals at the three field locations who assisted in the installation and commissioning of the dew point monitoring instrumentation in their facilities. In this regard, we appreciate the cooperation of the plants' managements and their engineering, operations, and maintenance staffs.

\section{REFERENCES}

[1] a) Wilkes, C. and Dean, A J. 1997 "Gas Fuel Conditioning Design Considerations for Utility Gas Turbines” ASME 97GT-227.

[2] Newbound, T. D. and Wagiealla, W. S. 2003 "On-Line Hydrocarbon Dew Point Monitoring in Fuel Gas” ASME GT2003-38868.

[3] a) Newbound, T. D. and Norek, R. S. 1997 "Contaminants in a Gas Turbine Fuel System and Thermal Shock” ASME 97-GT-307. b) Norek, R.S. 1992 “Operating Experience with Nozzles and Blades in MS-5002 Gas Turbines in a Desert Environment", Presented at the Steam and Combustion Turbine Blading Conference, Orlando FL, Jan. 29-31, 1992. Proceedings published by Electric Power Research Institute in cooperation with Edison Electric Institute.

[4] Baldwin, R.M. 1998 "Black Powder in the Gas Industry" SRI Mechanical and Fluids Engineering Division Technical Assessment published by Gas Machinery Research Council. 


\section{Professional Profile}

Timothy D. Newbound studied chemistry at Eastern Michigan University, where he received a B.S. degree. He continued his education at University of Utah, earning a Ph.D. in Inorganic Chemistry in 1988. Tim's interest turned to the oil and gas industry in 1989 when he joined the Saudi Aramco. There he began his work as an analytical scientist solving various industrial problems, and he eventually developed research and technology projects in gas processing and natural gas and NGL distribution systems. His special interests in this area are fuel conditioning for combustion gas turbines, methods of measuring hydrocarbon and water dew points in natural gas, and methods for measuring entrained corrosion inhibitor residual and solids in natural gas streams. Tim has published several papers related to gas turbine fuels, and his paper entitled "Tuning your Fuel Gas Delivery System" was awarded the ASME Oil and Gas Division "2004 Best Paper Award". More recently, Tim was credited with a U.S. patent for gas sampling technology known as Adsorption Trap Technology (ATT). He is currently developing commercial applications using ATT for measuring entrained solids and surface-active agents in natural gas streams. 